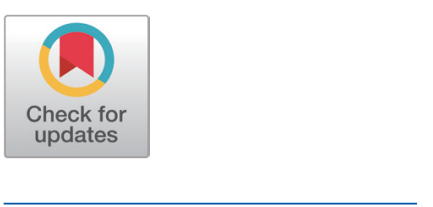

Received: Jul 10, 2020

Revised: Sep 11, 2020

Accepted: Oct 2, 2020

\#These authors contributed equally to this work.

${ }^{*}$ Corresponding author Mingxing Chu

Key Laboratory of Animal Genetics, Breeding and Reproduction of Ministry of Agriculture and Rural Affairs, Institute of Animal Science, Chinese Academy of Agricultural Sciences, Beijing 100193, China.

Tel: +86-10-62819850

E-mail: mxchu@263.net

Ran Di

Key Laboratory of Animal Genetics, Breeding and Reproduction of Ministry of Agriculture and Rural Affairs, Institute of Animal Science, Chinese Academy of Agricultural Sciences, Beijing 100193, China.

Tel: +86-10-62816001

E-mail: dirangirl@163.com

Copyright (c) 2020 Korean Society of Animal Sciences and Technology. This is an Open Access article distributed under the terms of the Creative Commons Attribution Non-Commercial License (http:// creativecommons.org/licenses/bync/4.0/) which permits unrestricted non-commercial use, distribution, and reproduction in any medium, provided the original work is properly cited.

ORCID

Lin Tao

https://orcid.org/0000-0002-8954-5706 Xiaoyun $\mathrm{He}$

https://orcid.org/0000-0002-2159-5635

\section{Luzhong mutton sheep: inbreeding and selection signatures}

\author{
Lin Tao ${ }^{1 \#}$, Xiaoyun He ${ }^{1 \#}$, Fengyan Wang ${ }^{1}$, Yingjie Zhong ${ }^{1}$, Linxiang Pan², \\ Xiangyu Wang ${ }^{1}$, Shangquan $\mathrm{Gan}^{3}$, Ran $\mathrm{Di}^{1 *}$ and Mingxing $\mathrm{Chu}^{1 *}$
}

${ }^{1}$ Key Laboratory of Animal Genetics, Breeding and Reproduction of Ministry of Agriculture and Rural Affairs, Institute of Animal Science, Chinese Academy of Agricultural Sciences, Beijing 100193, China

'Ji'nan Laiwu Yingtai Agriculture and Animal Husbandry Technology, Ji'nan, Shandong 271114, China

${ }^{3}$ State Key Laboratory of Sheep Genetic Improvement and Healthy Production, Xinjiang Academy of Agricultural and Reclamation Sciences, Shihezi, Xinjiang 832000, China

\begin{abstract}
Intense artificial selection has been imposed to Luzhong mutton sheep population in the past years. Improvements on growth and reproductive performance are two breeding goals in the present herd. Although some progresses were phenotypically observed possibly due to inbreeding induced by strong selection in terms of these traits, the genomic evaluation was poorly understood. Therefore, a high-density SNP array was used to characterize the pattern of runs of homozygosity $(\mathrm{ROH})$, estimate inbreeding and inbreeding depressions on early growth performance and litter size based upon $\mathrm{ROH}$, and scan positive selection signatures of recent population. Consequently, a low inbreeding level was observed which had negative effects on litter size, but not on early growth performance. And 160 genes were under selection, of which some were reported to be linked to several traits of sheep including body weight, litter size, carcass and meat quality, milk yield and composition, fiber quality and health, and the top genes were associated with growth (growth hormone [GH]- growth hormone receptor [GHR]- Insulin-like growth factor 1 [IGF1] axis) and litter size (bone morphogenic proteins [BMPs]-associated). The effectiveness of previous breeding measures was highlighted, but purging selection was proposed to alleviate the inbreeding depression on litter size, providing some genomic insights to breeding management of Luzhong mutton sheep.
\end{abstract}

Keywords: Inbreeding, Selection signatures, Birth weight, Body conformation, Litter size, Sheep

\section{INTRODUCTION}

Livestock plays an integral part in human civilization in terms of the early drafting performance and long-term supply of protein including meat, egg and dairy. High harvest is one principal objective for livestock production, leading to persistently intense artificial selection for economic traits, namely selective breeding. Only a few excellent individuals inevitably have an opportunity to generate offspring, especially the sire considering the maintaining cost and popularization of artificial insemination, which contributes to the decline of genetic diversity at the population and individual levels. Consequently, the phenomenon inbreeding, leading to increased homozygosity of progeny, always occurs in livestock 
Fengyan Wang

https://orcid.org/0000-0002-5609-3045

Yingjie Zhong

https://orcid.org/0000-0001-6688-1486

Linxiang Pan

https://orcid.org/0000-0002-4235-8196

Xiangyu Wang

https://orcid.org/0000-0001-7375-8937

Shangquan Gan

https://orcid.org/0000-0003-2880-7677

Ran Di

https://orcid.org/0000-0003-3450-738X

Mingxing Chu

https://orcid.org/0000-0002-5164-0310

\section{Competing interests}

No potential conflict of interest relevant to

this article was reported.

\section{Funding sources}

This research was funded by grants from the National Natural Science Foundation of

China (31861143012, 31772580), Earmarked

Fund for China Agriculture Research

System (CARS-38), Agricultural Science and Technology Innovation Program of China (ASTIP-IAS13), China Agricultural Scientific Research Outstanding Talents and Their Innovative Teams Program, China High-level Talents Special Support Plan Scientific and Technological Innovation Leading Talents Program (W02020274), Tianjin Agricultural Science and Technology Achievements Transformation and Popularization Program (201704020) and Joint Funds of National Natural Science Foundation of China and Government of Xinjiang Uygur Autonomous Region of China (U1130302)

\section{Acknowledgements}

The authors appreciate the help from the staffs of Ji'nan Laiwu Yingtai Agriculture and Animal Husbandry Technology and Chu's lab.

Availability of data and material The data set used in this study were deposited in Figshare (https://doi. org/10.6084/m9.figshare.9987965, and https://doi.org/10.6084/ m9.figshare.12052824).

\section{Authors' contributions}

Conceptualization: Di R, Chu M.

Data curation: Tao L, He X, Wang F.

Formal analysis: Tao L, He X, Zhong Y.

Methodology: Chu M, Di R.

Software: Tao L, He X, Pan L.

Validation: Tao L, He X, Wang X.

Investigation: Tao L, He X, Gan S.

Writing - original draft: Tao L, He X.

Writing - review \& editing: Tao L, He X, Wang F,

Zhong Y, Pan L, Wang X, Gan S, Di R,

Chu M.

Ethics approval and consent to participate All experimental procedures and animal collections were conducted under a permit (No. IAS2018-3) approved by the Institutional Animal Care and Use Ethics Committee of Institute of Animal Science of Chinese Academy of Agricultural Sciences. breed, coupled with the reduction in evolutionary fitness of the next generation referred to as inbreeding depression [1]. As a result of inbreeding depression, it is hard to maintain superior performance, even normal fitness for individuals. More attention was poured to the selection on growth performance and reproductive traits in livestock production, and it is worth noting the potentially negative effects of inbreeding depression on these traits. Therefore, the pros and cons of selective inbreeding are apparent, where one is the improvement of productive performance, and another is the risk of inbreeding depression. It has been reported that inbreeding depression occurs in numerous animals, including pigs [2], cattle [3], horses [4], sheep [5], goats [6], chickens [7] and dogs [8]. Hence, crucial to the effective breeding management is the regularly genetic monitoring and assessment of inbreeding.

The classic method to evaluate inbreeding depression is based on fitness-related traits from individuals with grouped inbreeding, which is measured by the probability of inheriting two alleles identical-by-descent at an autosomal locus in the presence of consanguinity, with so-called inbreeding coefficient [1,9]. Traditionally, inbreeding coefficient was calculated based upon pedigrees involved in thousands of individuals; however, recent estimates of inbreeding coefficient relying on genomic data were recommended for the sake of accuracy and convenience without the relatives of subjects [10].

Apart from artificial selection, natural selection also acts in farm animals to adapt various environments via three ways (positive selection, background selection and balance selection) [11]. Both selections can shape individual genome, resulting in genomic footprints of selection called signatures of selection, of which the whole-genome scan can return genetic information to disclose possibly genetic makeup of adaptive evolution, to identify promising genes responsible for importantly agronomic traits, to estimate the development of herds, and to provide some management strategies [12]. The emergence of a plethora of algorithms and software for detecting selective sweeps provides an opportunity to decipher the genetic architecture of given phenotypes.

Intense artificial selection has been imposed to Luzhong mutton sheep population in the past years. Improvements on growth and reproductive performance are two breeding goals in the present herd. Although some progresses were phenotypically observed compared to the unselected population (F2), such as birth weight ( $4.04 \pm 0.06$ vs $3.36 \pm 0.03 \mathrm{~kg}, p<0.05, t$-test), and average litter size (1.91 \pm 0.07 vs $1.37 \pm 0.03, p<0.05$, Mann-Whitney $U$-test), the genomic evaluation was poorly understood. Therefore, the objectives of this study were to characterize the pattern of runs of homozygosity $(\mathrm{ROH})$, estimate the effects of inbreeding on early growth and productive performance, and detect signatures of positive selection based upon haplotypes in Luzhong mutton sheep.

\section{MATERIALS AND METHODS}

\section{Animals and genotypes}

In total, the blood samples of 345 Luzhong mutton sheep under intensive feeding were collected from Ji'nan Laiwu Yingtai Agriculture and Animal Husbandry Technology (N36 17'33.25" E117'35'14.98", Ji' nan, Shandong, China) for extraction of genomic DNA using a QIAamp DNA Blood Midi Kit (Qiagen, Germany), of which 277 animals harbored records of birth weight and body conformation traits at birth including body length, chest girth and withers height, and 70 individuals held reproductive performance (specifically, litter size) of at least two parities. Each 15 individuals were kept in one pen with $3 \mathrm{~m}^{2} / \mathrm{animal}$, and all ewes were $\sim 3.5 \mathrm{~kg}$ fed silage maize, $\sim 1$ $\mathrm{kg}$ concentrate feed mixture, and ad libitum water. All animals were genotyped by a high-density SNP (single nucleotide polymorphism) chip featured by 633,619 markers, followed by quality control using PLINK v1.90 [13] with criteria: (1) call rate $\geq 90 \%$; (2) minor allele frequency $\geq 1 \%$; (3) 
$p$-value of Hard-Weinberg disequilibrium test $\geq 10^{-6}$; (4) sample call rate $\geq 95 \%$; and (5) markers on autosomes. The data set used in this study were deposited in Figshare (https://doi.org/10.6084/ m9.figshare.9987965, and https://doi.org/10.6084/m9.figshare.12052824), partly accessible in previous work [14].

Runs of homozygosity calling, runs of homozygosity hotspots and inbreeding estimations

ROH calling was performed by PLINK v1.90 [13] with following parameters: (1) length of ROH $\geq 500 \mathrm{~kb}$; (2) number of SNPs within ROH $\geq 100$; (3) density of marker $\geq$ one SNP per $50 \mathrm{~kb}$; and (4) the gap between proximal two SNPs $\leq 1,000 \mathrm{~kb}$. One heterozygote and five missing calls were allowed within the sliding window of 5,000 kb. Moreover, "--homozyg-group" command in PLINK v1.90 [13] was executed to identify homozygous identical segments among individuals referenced as to $\mathrm{ROH}$ hotspots, which was defined as the segments with length over $1 \mathrm{~kb}$ and shared by at least 173 animals $[(345+1) / 2=173]$. Genomic inbreeding coefficients based on $\mathrm{ROH}\left(\mathrm{F}_{\mathrm{ROH}}\right)$ were estimated by the proportion of the total length of $\mathrm{ROH}$ on all autosomes $(2,655.71 \mathrm{Mb}$ used in this study).

\section{Inbreeding effects on early growth and reproductive performance}

All animals were divided into three categories based on $F_{\mathrm{ROH}}$, including $\mathrm{F}_{\mathrm{ROH}}<0.01,0.01 \leq \mathrm{F}_{\mathrm{ROH}}$ $\leq 0.1$ and $F_{\mathrm{ROH}} \geq 0.1$. For early growth performance traits, we investigated the effects of genomic inbreeding coefficient categories, taking sex as a fixed factor in the model. Tukey method was used to paired comparison, declaring significance at $p$ level of 0.05 . For litter size of the first and second parity, average litter size of the first two parities, and average litter size, one-way ANOVA was employed to explore the effect of inbreeding coefficients, accepting significance of 0.05 . Moreover, we regressed both early growth and reproduction performance for each sheep against $\mathrm{F}_{\mathrm{ROH}}$ to assess inbreeding depression.

\section{Positive selection signatures in Luzhong mutton sheep}

To investigate the genomic footprints left by selection in the present population, the statistic number of segregating sites by length (nSL) [15], a log-ratio of the SL statistic calculated for the ancestral and derived haplotype pools, was employed to detect selective sweeps considering soft sweeps. Haplotypes were phased severally for autosomes using shapeit v2.12, followed by nSL calculation by selscan v1.2.0, and normalization with norm [16,17]. Top 5\% loci were considered as candidates and annotation to sheep reference genome Oar_v4.0 was performed by Variant Annotation Integrator online. DAVID (accessed April 19, 2020), STRING (accessed April 22, 2020) and Animal QTLdb (accessed April 22, 2020) database were used for functional annotation and interactions of candidate genes.

\section{RESULTS}

\section{Quality control}

Overall, sample genotyping rate was $98.34 \%$. As a consequence of quality control, 522,102 SNPs and 345 samples passed filters, during which 30,061 variants were removed due to missing genotype data, 9,648 Hardy-Weinberg exact test, and 71,808 minor allele frequency.

\section{Pattern of runs of homozygosity and runs of homozygosity hotspots}

A total of 22,821 ROHs were found in the present population. At the individual level, the number 
of $\mathrm{ROH}$ ranged from 1 to 170 , the total length $532 \mathrm{~kb}$ to $745,382 \mathrm{~kb}$, and the average length 532 $\mathrm{kb}$ to $8,191 \mathrm{~kb}$ (Fig. 1A). According to the length, all ROHs were grouped into three classes, showing a large proportion were short $(<2 \mathrm{Mb})$ (Fig. 1B).

In total, ten $\mathrm{ROH}$ hotspots were identified, including three on chromosome 1 and seven on chromosome 10 (Table 1). None gene was found on seven $\mathrm{ROH}$ hotspots on chromosome 10, whereas two genes were discovered on three ROH hotspots on chromosome 1, containing STAG1 (stromal antigen 1) involved in cell cycle and $P C C B$ (propionyl-CoA carboxylase subunit beta) participating in metabolism.

\section{Genomic inbreeding coefficients and inbreeding effects}

Genomic inbreeding coefficients $\mathrm{F}_{\mathrm{ROH}}$ ranged from 0.0002 to 0.2807 , with an average of 0.0649 , indicating a low level of inbreeding in the present population. There were no significant differences between the category of genomic inbreeding coefficients $\left(\mathrm{F}_{\mathrm{ROH}}<0.01,0.01 \leq \mathrm{F}_{\mathrm{ROH}} \leq 0.1\right.$ and $\mathrm{F}_{\mathrm{ROH}}$ $>0.1$ ) in terms of early growth performance traits, harboring birth weight and body conformation at birth (withers height, body length and chest girth) (Fig. 2). However, compared to ewes with low inbreeding coefficients $\left(\mathrm{F}_{\mathrm{ROH}}<0.01\right)$, remarkable diminishes of litter size were observed for these with high inbreeding except the first parity $(p<0.05)$, implying the presence of inbreeding depres-
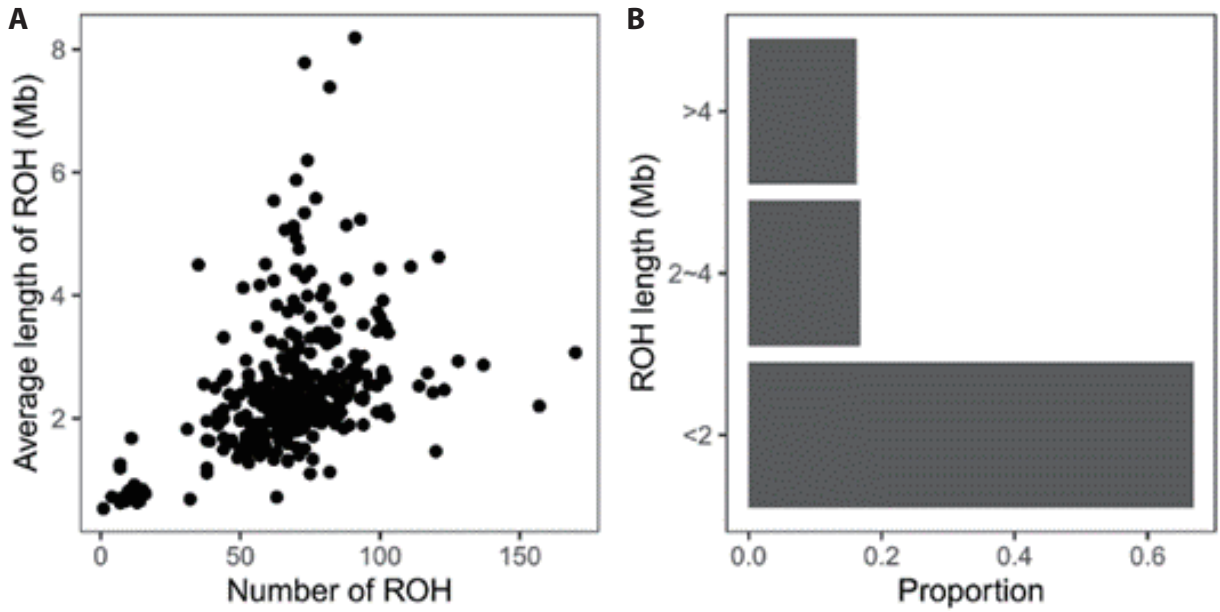

Fig. 1. Pattern of runs of homozygosity (ROH) in Luzhong mutton sheep.

Table 1. ROH hotspots in Luzhong mutton sheep

\begin{tabular}{|c|c|c|c|c|c|c|}
\hline ROH hotspot & Chromosome & Animal number & Location & Length/kb & SNP number & Gene \\
\hline S1 & 1 & 200 & $250760447-250784473$ & 24.027 & 6 & STAG1 \\
\hline S2 & 1 & 192 & $250850180-250856729$ & 6.55 & 4 & PCCB \\
\hline S3 & 1 & 180 & $250899911-250902751$ & 2.841 & 2 & PCCB \\
\hline S4 & 10 & 179 & $43244596-43294037$ & 49.442 & 12 & - \\
\hline S5 & 10 & 179 & $43319122-43323886$ & 4.765 & 3 & - \\
\hline S6 & 10 & 178 & $43351505-43498678$ & 147.174 & 24 & - \\
\hline S7 & 10 & 176 & $42592740-42676739$ & 84 & 17 & - \\
\hline S8 & 10 & 176 & $42845024-43014163$ & 169.14 & 29 & - \\
\hline S9 & 10 & 176 & $43016731-43037870$ & 21.14 & 3 & - \\
\hline S10 & 10 & 173 & $42425378-42457347$ & 31.97 & 9 & - \\
\hline
\end{tabular}

$\mathrm{ROH}$, runs of homozygosity; SNP, single nucleotide polymorphism; STAG1, stromal antigen 1; PCCB, propionyl-CoA carboxylase subunit beta. 

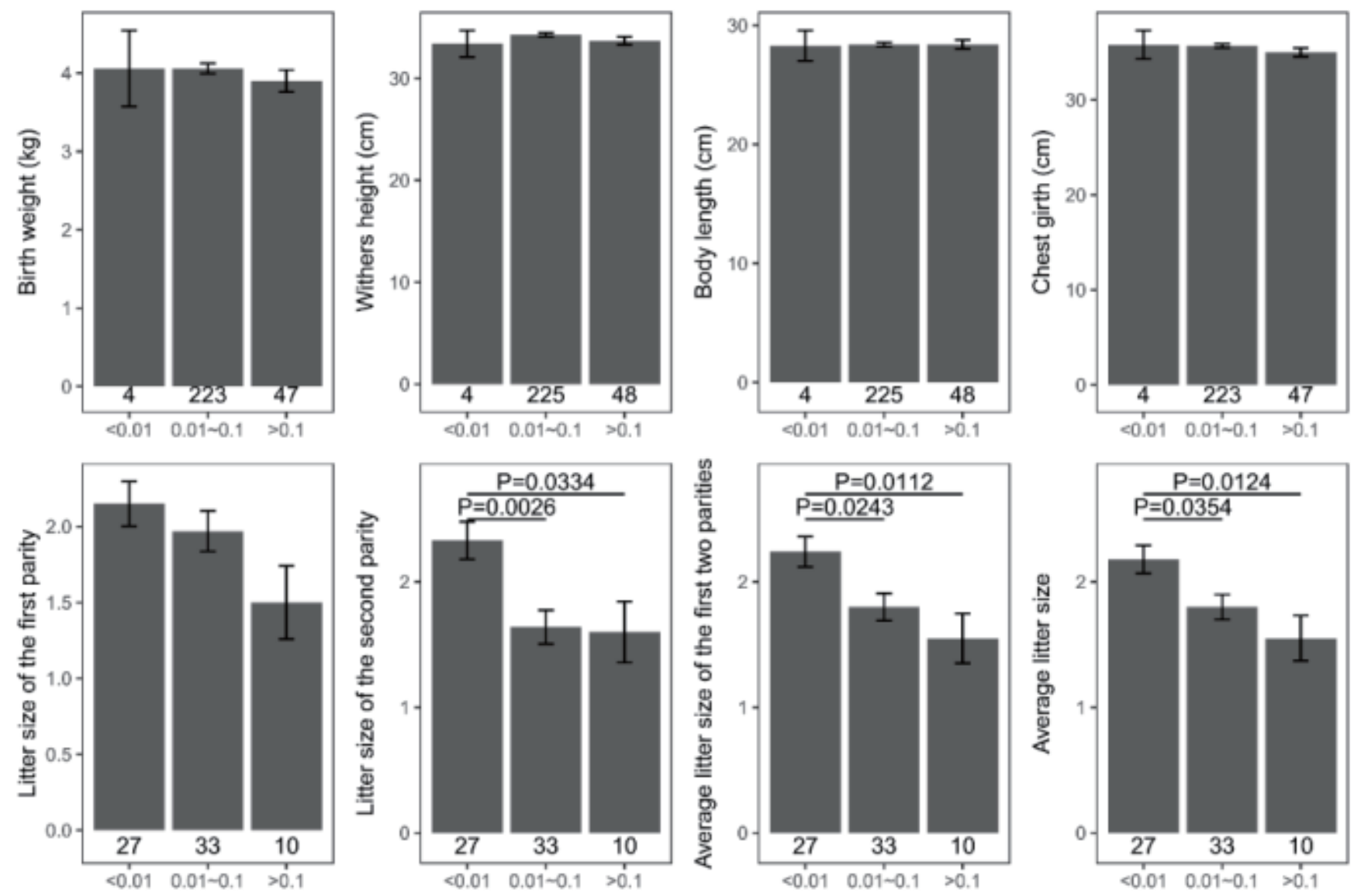

Fig. 2. Early growth performance and litter size against category of genomic inbreeding coefficients $\left(\mathrm{F}_{\mathrm{ROH}}\right)$. The number under each bar donates sample size. $\mathrm{ROH}$, runs of homozygosity.

sion on reproductive performance in this population (Fig. 2). Moreover, linear regression analysis of birth weight, body conformation at birth and litter size was performed to explore the effects of inbreeding on early growth performance and reproductive capacity. As a consequence, albeit the absence of valid regression for early growth performance and the presence of poor fitting degree for litter size, a trend of decline for litter size was observed based on negative regression coefficients, suggesting potential inbreeding depression on both reproductive traits in Luzhong mutton sheep (Fig. 3).
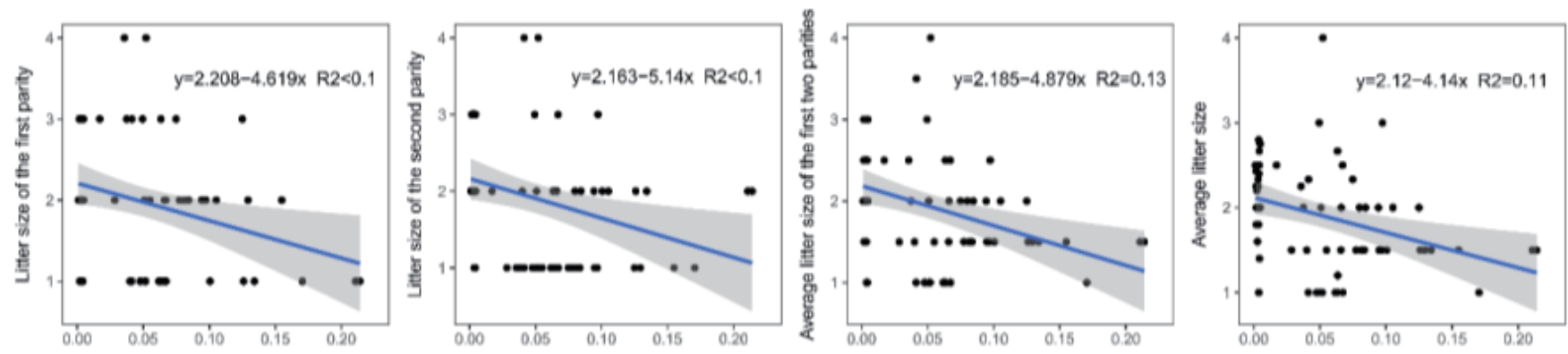

Fig. 3. Linear regressions of litter size against genomic inbreeding coefficients $\left(F_{\mathrm{ROH}}\right)$. ROH, runs of homozygosity. 


\section{Selection signatures and annotation of candidate genes}

The results of selective sweeps were shown in Fig. 4. A total of 160 candidate genes were identified for the top 5\% loci, which were enriched to 87 gene ontology (GO) terms including 59 biological process terms, 18 cell component terms and ten molecular function terms, and 52 Kyoto Encyclopedia of Genes and Genomes (KEGG) pathways, respectively. Of these genes, signal transducer and activator of transcription 5A (STAT5A) with extensive functions was found with highest $|\mathrm{nSL}|$, followed by two hormone-related genes follistatin (FST) on chromosome 16 and PTGER2 (prostaglandin E receptor 2) on chromosome 7. Extensive and fundamental roles in cell component and molecular function were observed for most candidate genes under selection (Fig. 5). These genes were involved in some important biological processes such as regulation of cell proliferation (GO:0043066, GO:0008284 and GO:0008285), immune response (GO:0006955), regulation of protein function (GO:0050731 and GO:0033138), signal transduction (GO:0000187 and GO:0007264), and biochemical function (GO:0045944 and GO:0006351) (Fig. 5). Significant KEGG pathways include numerous diseases, immunoregulation, metabolism, signaling pathways, and steroid hormone biosynthesis (Fig. 6). To explore the relationship between candidate genes, the primary interactions network was represented in Fig. 7. In total, 19 genes were found in Animal

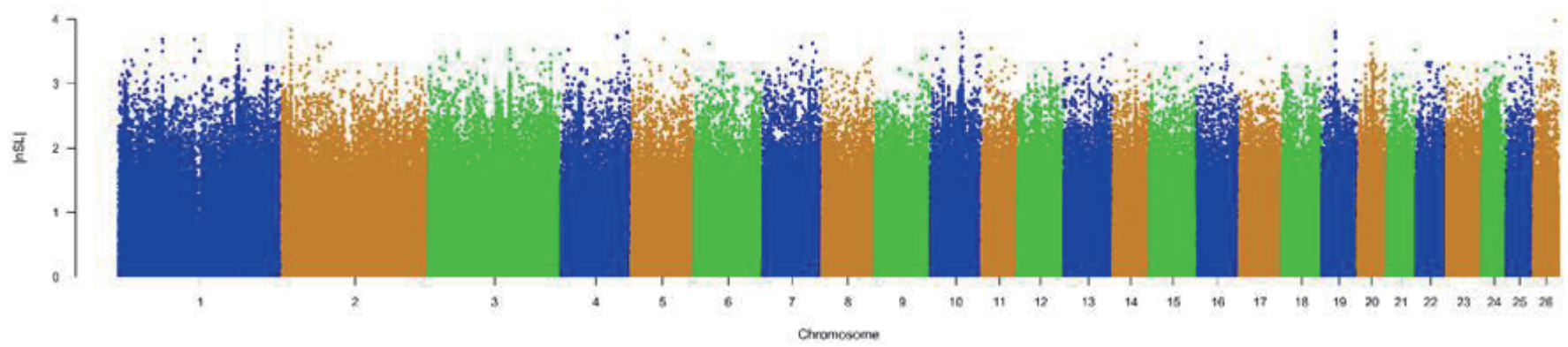

Fig. 4. Manhattan plot of selective sweeps on autosomes. Top $5 \%$ with a |nSL| cutoff of 2 were considered as candidate loci for which 160 protein-coding genes were annotated. nSL, number of segregating sites by length.

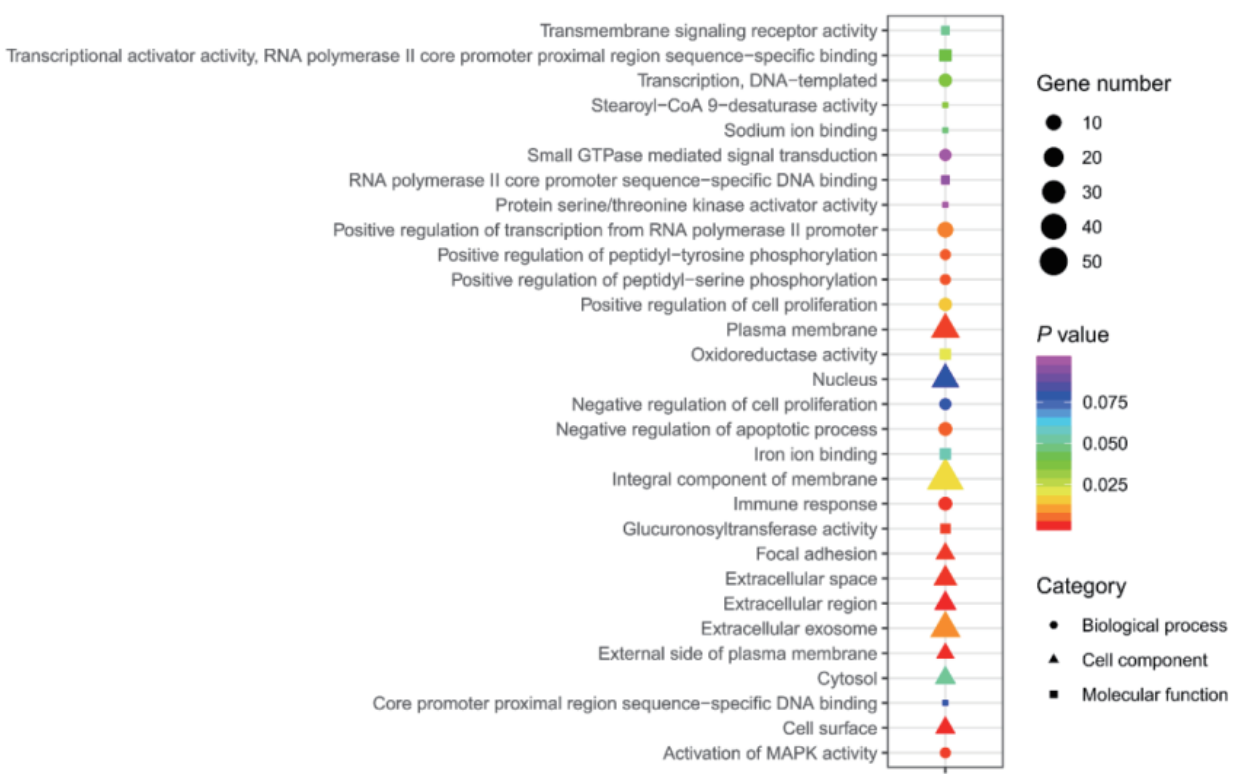

Fig. 5. Top $10 \mathrm{GO}$ terms for each category of candidate genes. GO, gene ontology. 


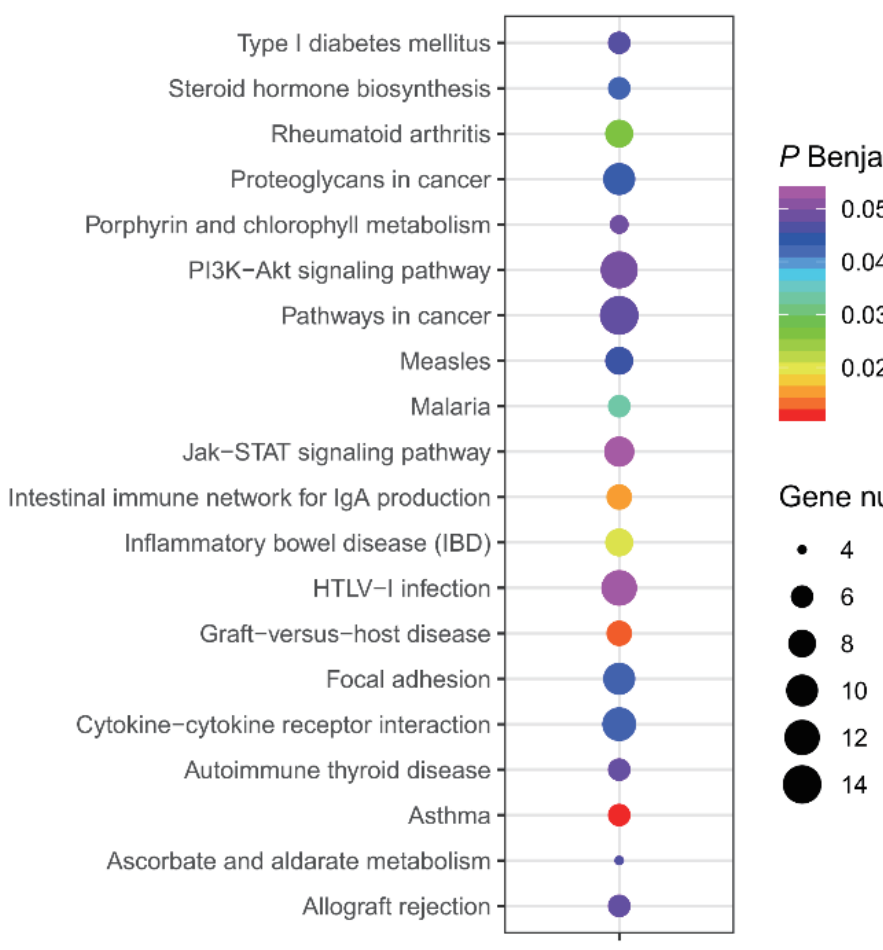

Fig. 6. Significant KEGG pathways of candidate genes. KEGG, Kyoto Encyclopedia of Genes and Genomes.

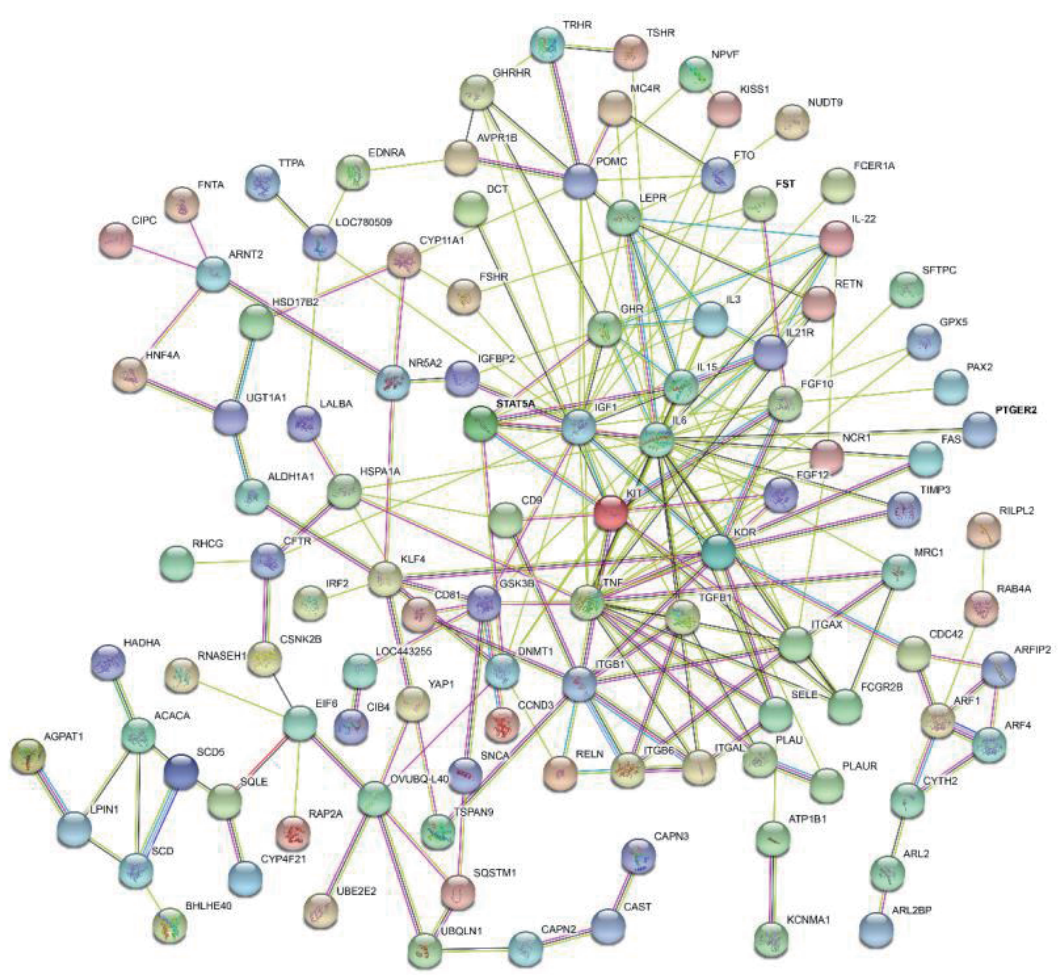

Fig. 7. Primary interactions of candidate genes. Isolated genes were removed. Nodes: colored nodes, query proteins and first shell of interactors; white nodes, second shell of interactors; empty nodes, proteins of unknown 3D structure; filled nodes, some 3D structure is known or predicted. Edges: dark turquoise, from curated databases; purple, experimentally determined; green, gene neighborhood; red, gene fusions; blue, gene co-occurrence; pale yellow, textmining; black, co-expression; pale blue, protein homology. 
QTLdb for several traits, including growth and development, reproduction, carcass and meat quality, milk composition, fiber quality, and parasite/diseases resistance (Table 2).

\section{DISCUSSION}

High harvest is one principal goal of selective breeding in livestock, during which phenotypical and genetic evaluation are always needed to monitor the achievement of breeding. Here, we evaluated

Table 2. Known function of genes under selection in sheep ${ }^{1)}$

\begin{tabular}{|c|c|c|}
\hline Trait class & Trait & Gene \\
\hline \multirow[t]{4}{*}{ Growth and development } & Body weight & GHR, MB, LEPR, GHRHR, CAST \\
\hline & Average daily gain & LEPR \\
\hline & Shin circumference & $M B$ \\
\hline & Curd firmness & FAS, LALBA \\
\hline \multirow[t]{6}{*}{ Reproduction } & Litter size & $F S H R, G H R, M B$ \\
\hline & Age at first lambing & $M B$ \\
\hline & Teat number & $M B$ \\
\hline & Interval between first and second lambing & $M B$ \\
\hline & Age at puberty & LEPR \\
\hline & Testes weight & TGFB1 \\
\hline \multirow[t]{11}{*}{ Carcass and meat quality } & Backfat at 12 th/13th ribs & GHR, GHRHR, CAST \\
\hline & Backfat at third lumbar & $M B$ \\
\hline & Carcass length & GHR \\
\hline & Hot carcass weight & GHR \\
\hline & Lumbar vertebra number & $M B$ \\
\hline & Lumbar weight & $M B$ \\
\hline & Subcutaneous fat thickness & $M B$ \\
\hline & Muscle depth at third lumbar & $M B, A C A C A$ \\
\hline & Tail fat deposition & $M B$ \\
\hline & Abdominal fat weight & GHR \\
\hline & Longissimus muscle area & SCD5 \\
\hline \multirow[t]{3}{*}{ Milk } & Yield & $M B$ \\
\hline & Curd firming time & FAS, LALBA \\
\hline & Composition & $\begin{array}{l}\text { GHR, MB, GHRHR, FAS, ITGB1, IGF1, ACACA, TGFB1, } \\
\text { STAT5A }\end{array}$ \\
\hline \multirow[t]{6}{*}{ Fiber quality } & Greasy fleece weight & $M B$ \\
\hline & Mean fiber diameter & $M B, F S T$ \\
\hline & Fiber diameter coefficient of variance & $M B, F S T$ \\
\hline & Fiber diameter standard deviation & $M B, F S T$ \\
\hline & Wool crimp & FST \\
\hline & Staple length & TGFB1 \\
\hline \multirow[t]{6}{*}{ Health } & Haemonchus contortus resistance & $M B$ \\
\hline & Fecal egg count & MB \\
\hline & Maedi-Visna virus susceptibility & MB, TMEM154 \\
\hline & Pneumonia susceptibility & MB, KCNMA1, IL6 \\
\hline & Facial eczema susceptibility & $M B$ \\
\hline & Scrapie susceptibility & $M B$ \\
\hline
\end{tabular}

\footnotetext{
${ }^{11}$ This table is based on the information searched in Animal QTLdb (accessed April 22, 2020) database.
}

$G H R$, growth hormone receptor; $M B$, myoglobin; $L E P$, leptin receptor; GHRHR, growth hormone releasing hormone receptor; CAST, calpastatin; FAS, Fas cell surface death receptor; $L A L B A$, lactalbumin alpha; FSHR, follicle stimulating hormone receptor; TGFB1, transforming growth factor beta 1; ACACA, acetyl-CoA carboxylase alpha; SCD5, stearoyl-CoA desaturase 5; ITGB1, integrin subunit beta 1; IGF1, insulin like growth factor 1; STAT5A, signal transducer and activator of transcription 5A; FST, follistatin; KCNMA1, potassium calcium-activated channel subfamily M alpha 1; IL6, interleukin 6. 
the genomic inbreeding grounded on homozygosity and its effects on early growth performance and litter size, detected positive selection signatures based upon haplotype using a high-density SNP array, which may provide some useful information for breeding progress on Luzhong mutton sheep.

\section{Inbreeding and inbreeding effects}

There was a long time when genetic evaluation for farm animals depended on pedigree data involved in thousands of individuals from several decades, which frequently contained parentage errors. Fortunately, genomic data provide an opportunity to get accurate and convenient assessments for animals in a lack of pedigrees. Inbreeding is a good example in this point in that some genetic inbreeding coefficients have been developed, of which $\mathrm{F}_{\mathrm{ROH}}$, the proportion of total $\mathrm{ROH}$ length on genomic autosomes, has been fully recognized. Inbreeding, mating between related animals, increases the genomic homozygosity of offspring. Longer $\mathrm{ROH}$ are expected in individuals with higher inbreeding degrees. We found a large proportion of short $\mathrm{ROH}(<2 \mathrm{Mb})$, implying a low inbreeding degreed in our population. It also was demonstrated by a low estimator of inbreeding coefficients (on average 0.0649 ). Indeed, this population is a new line with a relatively short breeding history. Hence, it was unsurprising that inbreeding depressions were not observed on early growth performance. Albeit low inbreeding and small sample size, inbreeding depressions on litter size were detected in this study, probably due to the accurate estimator of inbreeding coefficients. Some hypotheses have been developed for inbreeding depression that it is caused by homozygosity of rare lethal, homozygosity of variants maintained by overdominance, nearly recessive variants and partially recessive, detrimental variants $[9,18,19]$. One possible explanation to the inbreeding depressions on litter size in low inbreeding population is that some major detrimental loci have been recessive homozygous, implying the importance and urgency of identifying these loci. Avoiding the occurrence of inbreeding depression is one approach to maintain the performance of herds. To reduce high inbreeding depression, minimizing inbreeding or mean kinship by reducing the weight given to family information at the selection step or optimal contribution selection, purging induced by deliberate inbreeding and genetic rescue (called hybridization in farm animals) can be implemented to manage a population [9]. Considering the low and slow inbreeding level in the current population, purging is effective to reduce or eliminate detrimental variants. To do this, following with subdividing the population into isolated lines, between-lines selection can increase purging [20], where the caveat is that elevated genetic drift will reduce overall genetic diversity. Alternatively, another strategy is to induce inbred mating, not increasing drift [21].

\section{Genes related with growth and development}

Improvement on growth performance is one of the breeding objectives of Luzhong mutton sheep population. Expectedly, several genes linked to body weight were identified by selective sweep analysis, such as growth hormone receptor $(G H R)$, insulin-like growth factor 1 (IGF1), growth hormone releasing hormone receptor $(G H R H R)$ and leptin receptor $(L E P R)$. The growth hormone $(G H)$ was known to modulate growth via the GH-GHR-IGF1 axis [22]. GH promotes body growth by binding dimerized GHRs to form a trimolecular complex, inducing downstream signaling pathways such as Janus kinase 2 (JAK2) activation, STATs, SRC family kinase (SFK), and JAK-STAT signaling [23]. Interestingly, the strongest selection signature was identified on STAT5A, which plays a vital role in GH-GHR-IGF1 axis [23,24]. Skeletal growth and mineral acquisition were regulated by GHR by the GH/IGF1 axis in mice [25]. Polymorphisms on GHR, GHRHR, and $I G F 1$ were found to be associated with milk yield and quality traits in Sarda sheep [26], indicating the roles of these genes in controlling offspring's early growth through nutritional 
regulation. LEPR is the receptor of leptin which is a hormone synthesized by adipocytes and influences development, growth, metabolism and reproduction [27]. It is important to note that leptin binds to LEPR, followed by downstream JAK2 activation and STAT3 signaling [28,29], suggesting the potential interaction between LEPR and GH-GHR-IGF1 axis.

\section{Genes associated with litter size}

Another breeding objective of the present population is to increase litter size by marker-assisted selection of $F e c B$ BB genotype on BMPR1B (bone morphogenetic protein receptor type 1B). Although known $B M P R 1 B$ did not emerge from selective sweep, several related genes including follicle-stimulating hormon receptor (FSHR), GHR and FST were found to be under selection in this study. Polymorphisms of FSHR were reported to be associated with litter size of some prolific breeds including Small Tail Han, Hu, Hetian and Bashbai sheep [30-33]. It is also important to note that GHR has been identified as a candidate gene for litter size of Texel sheep in a genome-wide associated study [34]. FSHR and GHR, the receptor of follicle-stimulating hormone and growth hormone, interact with BMPR1B to act as important regulators in the development of follicle. Interestingly, the patterns of DNA methylation on BMPR1B, FST and FSHR may participate in the regulation of ovine fecundity [35]. Folliculogenesis was modulated by pituitary gonadotrophins and intraovarian growth factors including epidermal growth factor (EGF), fibroblast growth factor (FGF), transforming growth factor- $\alpha$ (TGF- $\alpha$ ), TGF- $\beta$, IGFs, IGF-binding proteins (IGFBPs), growth differentiation factor 9 (GDF-9), BMPs, inhibin, activin and FST [36], of which some genes were under selection in our study. It is interesting to note that FST, coding FST, was identified with top $2|\mathrm{nSL}|$ value. The expression location of FST mRNA and protein within ovary is granulosa cell in antral follicles and luteinized granulosa cell [37], suggesting the role of FST in regulating follicular development. FST is a binding protein belonging to the TGF- $\beta$ superfamily, acting as an inhibitory by binding to other members of the TGF- $\beta$ superfamily including activin, BMP-4, BMP-7, BMP-15, and GDF-8, which play curial roles in ovarian function [36]. The increased FST in ovary decreased the number of FSH and LH receptors in granulosa cells, progesterone level in undifferentiated granulosa cells and estrogen level, and increased progesterone level in differentiated granulosa cells and androgen, leading to the suppression of oocytes in terms of meiotic and cytoplasmic maturation, and developmental competence to form blastocysts [36]. Together, genes associated with litter size have been under selection, suggesting the effectiveness of selective breeding on litter size in Luzhong mutton sheep. However, more work is needed to disclose potential causative variations for litter size in the current population.

To sum up, we estimated genomic inbreeding and its effects on early growth and reproductive performance based on whole-genome homozygosity, and detected selection signatures based upon haplotypes to evaluate the breeding progresses on the recent herd. Accordingly, purging selection was proposed to alleviate the inbreeding depression on litter size. Selective sweeps on genes associated with growth and litter size highlighted the effectiveness of the persistent selective breeding in Luzhong mutton sheep population. These results provide novel insights to evaluate breeding progresses on livestock, and are in favor in genetic improvement of the present flock.

\section{REFERENCES}

1. Ceballos FC, Joshi PK, Clark DW, Ramsay M, Wilson JF. Runs of homozygosity: windows into population history and trait architecture. Nat Rev Genet. 2018;19:220-34. https:/doi. org/10.1038/nrg.2017.109

2. Casellas J, Ibáñez-Escriche N, Varona L, Rosas JP, Noguera JL. Inbreeding depression load 
for litter size in Entrepelado and Retinto Iberian pig varieties. J Anim Sci. 2019;97:1979-86. https://doi.org/10.1093/jas/skz084

3. Doekes HP, Veerkamp RF, Bijma P, de Jong G, Hiemstra SJ, Windig JJ. Inbreeding depression due to recent and ancient inbreeding in Dutch Holstein-Friesian dairy cattle. Genet Sel Evol. 2019;51:54. https://doi.org/10.1186/s12711-019-0497-z

4. Bussiman FO, Perez BC, Ventura RV, Peixoto MGCD, Curi RA, Balieiro JCC. Pedigree analysis and inbreeding effects over morphological traits in Campolina horse population. Animal. 2018;12:2246-55. https://doi.org/10.1017/s175173111800023x

5. Barczak E, Wolc A, Wójtowski J, Ślósarz P, Szwaczkowski T. Inbreeding and inbreeding depression on body weight in sheep. J Anim Feed Sci. 2009;18:42-50. https://doi.org/10.22358/ jafs/66366/2009

6. Mahmoudi P, Rashidi A, Razmkabir M. Inbreeding effects on some reproductive traits in Markhoz goats. Anim Prod Sci. 2018;58:2178-83. https://doi.org/10.1071/an17043

7. Tongsiri S, Jeyaruban GM, Hermesch S, van der Werf JHJ, Li L, Chormai T. Genetic parameters and inbreeding effects for production traits of Thai native chickens. Asian-Australas J Anim Sci. 2019;32:930-8. https://doi.org/10.5713/ajas.18.0690

8. Chu ET, Simpson MJ, Diehl K, Page RL, Sams AJ, Boyko AR. Inbreeding depression causes reduced fecundity in Golden Retrievers. Mamm Genome. 2019;30:166-72. https://doi. org/10.1007/s00335-019-09805-4

9. Hedrick PW, Garcia-Dorado A. Understanding inbreeding depression, purging, and genetic rescue.Trends Ecol Evol. 2016;31:940-52. https://doi.org/10.1016/j.tree.2016.09.005

10. Kardos M, Luikart G, Allendorf FW. Measuring individual inbreeding in the age of genomics: marker-based measures are better than pedigrees. Heredity. 2015;115:63-72. https://doi. org/10.1038/hdy.2015.17

11. de Simoni Gouveia JJ, da Silva MVGB, Paiva SR, de Oliveira SMP. Identification of selection signatures in livestock species. Genet Mol Biol. 2014;37:330-42. https://doi.org/10.1590/ S1415-47572014000300004

12. Bertolini F, Servin B, Talenti A, Rochat E, Kim ES, Oget C, et al. Signatures of selection and environmental adaptation across the goat genome post-domestication. Genet Sel Evol. 2018;50:57. https://doi.org/10.1186/s12711-018-0421-y

13. Purcell S, Neale B, Todd-Brown K, Thomas L, Ferreira MAR, Bender D, et al. PLINK: a tool set for whole-genome association and population-based linkage analyses. Am J Hum Genet. 2007;81:559-75. https://doi.org/10.1086/519795

14. Tao L, He XY, Pan LX, Wang JW, Gan SQ, Chu MX. Genome-wide association study of body weight and conformation traits in neonatal sheep. Anim Genet. 2020;51:336-40. https:// doi.org/10.1111/age.12904

15. Ferrer-Admetlla A, Liang M, Korneliussen T, Nielsen R. On detecting incomplete soft or hard selective sweeps using haplotype structure. Mol Biol Evol. 2014;31:1275-91. https://doi. org/10.1093/molbev/msu077

16. Delaneau O, Marchini J, Zagury JF. A linear complexity phasing method for thousands of genomes. Nat Methods. 2012;9:179-81. https://doi.org/10.1038/nmeth.1785

17. Szpiech ZA, Hernandez RD. Selscan: an efficient multithreaded program to perform EHHbased scans for positive selection. Mol Biol Evol. 2014;31:2824-7. https://doi.org/10.1093/ molbev/msu211

18. Howard JT, Pryce JE, Baes C, Maltecca C. Inbreeding in the genomics era: inbreeding, inbreeding depression, and management of genomic variability. J Dairy Sci. 2017;100:6009-24. https://doi.org/10.3168/jds.2017-12787 
19. Bosse M, Megens HJ, Derks MFL, de Cara ÁMR, Groenen MAM. Deleterious alleles in the context of domestication, inbreeding, and selection. Evol Appl. 2018;12:6-17. https://doi. org/10.1111/eva.12691

20. Wang JL. Effects of population structures and selection strategies on the purging of inbreeding depression due to deleterious mutations. Genet Res. 2000;76:75-86. https://doi.org/10.1017/ s0016672399004450

21. Bersabé D, Caballero A, Pérez-Figueroa A, García-Dorado A. On the consequences of purging and linkage on fitness and genetic diversity. G3: Genes Genomes Genet. 2016;6:171-81. https://doi.org/10.1534/g3.115.023184

22. Lin S, Li C, Li C, Zhang X. Growth hormone receptor mutations related to individual dwarfism. Int J Mol Sci. 2018;19:1433. https://doi.org/10.3390/ijms19051433

23. Dehkhoda F, Lee CMM, Medina J, Brooks AJ. The growth hormone receptor: mechanism of receptor activation, cell signaling, and physiological aspects. Front Endocrinol. 2018;9:35. https://doi.org/10.3389/fendo.2018.00035

24. Kopchick JJ. Lessons learned from studies with the growth hormone receptor. Growth Horm IGF Res. 2016;28:21-5. https://doi.org/10.1016/j.ghir.2015.06.003

25. Yakar S, Isaksson O. Regulation of skeletal growth and mineral acquisition by the GH/IGF1 axis: lessons from mouse models. Growth Horm IGF Res. 2016;28:26-42. https://doi. org/10.1016/j.ghir.2015.09.004

26. Dettori ML, Pazzola M, Paschino P, Amills M, Vacca GM. Association between the GHR, GHRHR, and IGF1 gene polymorphisms and milk yield and quality traits in Sarda sheep. J Dairy Sci. 2018;101:9978-86. https://doi.org/10.3168/jds.2018-14914

27. Denver RJ, Bonett RM, Boorse GC. Evolution of leptin structure and function. Neuroendocrinology. 2011;94:21-38. https://doi.org/10.1159/000328435

28. Cohen MM. Role of leptin in regulating appetite, neuroendocrine function, and bone remodeling. Am J Med Genet Part A. 2006;140A:515-24. https://doi.org/10.1002/ajmg.a.31099

29. Bates SH, Myers MG. The role of leptin receptor signaling in feeding and neuroendocrine function. Trends Endocrinol Metab. 2003;14:447-52. https://doi.org/10.1016/ j.tem.2003.10.003

30. Chu MX, Guo XH, Feng CJ, Li Y, Huang DW, Feng T, et al. Polymorphism of 5' regulatory region of ovine FSHR gene and its association with litter size in Small tail Han sheep. Mol Biol Rep. 2012;39:3721-5. https://doi.org/10.1007/s11033-011-1147-x

31. Wang W, Liu S, Li F, Pan X, Li C, Zhang X, et al. Polymorphisms of the ovine BMPR-IB, BMP-15 and FSHR and their associations with litter size in two chinese indigenous sheep breeds. Int J Mol Sci. 2015;16:11385-97. https://doi.org/10.3390/ijms160511385

32. Du X, Guo J, Cao QY, Yao W, Li QF. A haplotype variant of Hu sheep follicle-stimulating hormone receptor promoter region decreases transcriptional activity. Anim Genet. 2019;50:407-11. https://doi.org/10.1111/age.12794

33. Ma H, Fang C, Liu L, Wang Q, Aniwashi J, Sulaiman Y, et al. Identification of novel genes associated with litter size of indigenous sheep population in Xinjiang, China using specific-locus amplified fragment sequencing technology. PeerJ. 2019;7:e8079. https://doi.org/10.7717/ peerj. 8079

34. Xu SS, Gao L, Xie XL, Ren YL, Shen ZQ, Wang F, et al. Genome-wide association analyses highlight the potential for different genetic mechanisms for litter size among sheep breeds. Front Genet. 2018;9:118. https://doi.org/10.3389/fgene.2018.00118

35. Zhang Y, Li F, Feng X, Yang H, Zhu A, Pang J, et al. Genome-wide analysis of DNA methylation profiles on sheep ovaries associated with prolificacy using whole-genome Bisulfite se- 
quencing. BMC Genomics. 2017;18:759. https://doi.org/10.1186/s12864-017-4068-9

36. Lin SY, Morrison JR, Phillips DJ, de Kretser DM. Regulation of ovarian function by the TGF- $\beta$ superfamily and follistatin. Reproduction. 2003;126:133-48. https://doi.org/10.1530/ rep. 0.1260133

37. Muttukrishna S, Tannetta D, Groome N, Sargent I. Activin and follistatin in female reproduction. Mol Cell Endocrinol. 2004;225:45-56. https://doi.org/10.1016/j.mce.2004.02.012 